\title{
Using real options to value losses from cyber attacks
}

\section{G. Stevenson Smith}

is the John Massey Professor of Accounting at Southeastern Oklahoma State University in Durant, Oklahoma. He is the coauthor of Forensic and Investigative Accounting 2nd edition $(\mathrm{CCH}, 2005)$. His published research has appeared in numerous scholarly journals, and he writes a biannual column, Black Tech Forensics, covering high tech cybercrime methods and their prevention for the Journal of Forensic Accounting.

\section{Anthony J. Amoruso}

is an Assistant Professor of Accounting at West Virginia University whose teaching interests are in the financial accounting area and whose research interests are in forensic accounting and corporate social responsibility.

Keywords: real options, cyber attack, digital assets, cyber losses, hacking, cybercrime

Abstract When traditional assets are lost, the loss is typically considered to be the summation of the purchase price and the costs of labor and material used to put an asset into production, reduced by depreciation charges and insurance recoveries. With digital assets, traditional loss valuation fails to reflect the full loss to the company, as much of a digital asset's value is based on intangibles. Here, the argument is made that without a full valuation of digital assets, managers do not know the true loss they have experienced should the asset be lost. Consequently, optimal managerial decisions cannot be made. Real options analysis using binomial trees are suggested as a means to measure the full value of digital assets, and their resulting losses.

Journal of Digital Asset Management (2006) 2, 150-162. doi:10.1057/palgrave.dam.3650033

\section{INTRODUCTION}

Today, cyber attacks can be targeted against any business or organization with connections to the Internet, and a successful attack can destroy valuable digital assets. ${ }^{1}$ For our purposes, digital assets are considered to be electronic data sets having a future economic value and possessing legal proprietary rights. Examples of such assets are software, computer code, video games, digital images, WAV files, animations, digital records (such as databases, e-documents and e-books), e-tokens, webpages, PowerPoint presentations, and residual information held within a computer. ${ }^{2}$ When compared with physical assets, digital assets are distinguished by their ease of transferability and alteration. If these assets are damaged or destroyed, traditional loss valuation fails to capture the extent of the incurred loss. Without an understanding of all the variables that go into a loss determination, it is difficult to determine the full loss to a company's digital assets or to make informed business decisions.

There are several reasons for accurately quantifying asset losses from cyber attacks. First, correct loss valuation is necessary when reporting the attack to law enforcement authorities. In most jurisdictions, such crimes must exceed a specified dollar amount to be considered a statutory crime. ${ }^{3}$ Another reason to accurately value losses is for applying for insurance recoveries. Depending on its insurance coverage, an organization may be able to recover a portion of its losses from an insurance carrier. ${ }^{4} \mathrm{~A}$ third reason for accurate loss quantification is related to a company's ability to make good business decisions. For example, if return on investment comparisons are to be made, an assessment of the digital asset's value is required.

This article uses real options analysis as a means to estimate losses from cyber attacks. Other studies analyzing digital loss have focused on tangible costs as a means to estimate the losses from cyber attacks. For example, the basis of the I-CAMP projects and other analysis have evaluated cyber attack losses using wage-hour costs of reconstruction, lost opportunity costs and various quantitative measures. ${ }^{5-9}$ Yet, these evaluations have largely ignored the intangible values attached to digital assets. 
The intangible nature of digital assets and their losses exhibit characteristics different from those losses incurred when tangible assets are damaged. Suh and Han (2002) ${ }^{10}$ have recognized this disparity: ${ }^{11}$

\footnotetext{
"In quantitative risk analysis methods, the value of a tangible asset is based on its replacement cost. The methods do not measure the tangible asset value from the viewpoint of operational continuity. They estimate the value of an intangible asset from the judgment of a risk analyst" (Suh and Han, 2002, p. 5). ${ }^{10}$
}

The authors argue that all asset losses need to take into consideration business operational continuity as well as replacement costs. They argue that asset values are directly related to their importance to a company's business functions as well as the historical cost value of the asset itself. Their line of argument on operational continuity is used here as the basis for real options analysis.

In the past, real options analysis has been used to evaluate capital budget alternatives, but they have not been previously used to make intangible loss estimations. Here, losses from cyber attacks are first identified for a hypothetical company called Memo, and then three alternative methods of loss estimation are explained and compared.

\section{DEFINING CYBER ATTACKS}

A variety of descriptions can be used to define a cyber attack. A cybercrime is legally defined by the jurisdiction where the cyber attack was committed. It may be possible that within a specific jurisdiction, where the cyber attack was launched, the activity is not considered to be an illegal act. In this paper, a cyber attack is recognized as a malicious computer-to-computer assault instigated by a perpetrator whose intent is to damage, steal, or destabilize computer information or prevent entry into a network. It occurs over a network, but it does not have to involve the Internet as it can be a workplace crime. The usual purpose of a cyber attack is either extortion, financial fraud, gaining widespread access to computer resources, launching malicious attacks across the Internet, causing random damage, or stealing intellectual property, but these crimes do not have to follow any single criminal purpose. ${ }^{12}$ The cyber attacks methods considered here are:

1. Hacking attacks to gain unauthorized access. Usually these attacks are combined with stealing intellectual property, customer information, or sabotaging data files.

2. Designing fraudulent Internet websites combined with identity theft (called phishing).

3. Defacement of company websites.

4. Extortion combined with denial of service attacks.

5. Releasing malware (worms/viruses) into a network.

Each of these cyber attacks have the capability to cause damages extending far beyond the expenditures needed to repair networks and affected computers. These cyber attacks have the potential to damage important corporate partnering relationships and future business opportunities and their continuity. Depending on the seriousness of the attack, its after effect can include lost partnering relationships, delayed contract completion dates, and delays in new product releases. Consequently, the future fortunes of a company that has been successfully attacked are diminished.

Although virus attacks capture the public's eye, an e-business can be subjected to many other successful and costly cyber attacks. It is estimated that cyber frauds cost e-business between 5 and 8 per cent of their sales. ${ }^{13}$ These attacks have contributed to the demise of at least one online business, Egghead.com in 2001, as well as the temporary closure of Amazon's, eBay's, and Yahoo's websites in 2000. In January 2001, even Microsoft experienced outages and website shutdowns as hackers used a misaligned router to create electronic havoc and millions of dollars in damages. ${ }^{14}$

\section{CURRENTLY RECOGNIZED LOSSES FROM CYBER ATTACKS}

For the purpose of this paper, losses are considered to be damages to tangible assets or intangible losses to information or data, or the future business interests and resources of an organization. Additionally, intangible losses may 
occur as third-party perceived losses. Third-party perceived losses are the psychological or social losses that outside parties have attributed to an organization due to the occurrence of a loss event. Here the loss event under review is a crime arising from a cyber attack on a company's network.

Cyber losses occur from the unauthorized removal and sale of proprietary information; cost of reconstructing destroyed or stolen code; destruction from malicious software introduced into a network; loss of partnering relationships arising from the consequences of a cyber attack; cost and damages incurred in lawsuits after a cyber attack; systems checking and reconstruction expenses; lessening of a company's reputation; and the loss of shareholder confidence and market capitalization. ${ }^{15,16}$ Tangible losses are the summation of material and labor costs needed to reconstruct the asset. Yet, the most significant damage from a cyber attack comes from the intangible losses from the attack.

Unfortunately, it is difficult to quantify the damages from these attacks. Consider the losses incurred from virus or worm attacks in recent years. It is estimated that businesses have suffered $\$ 65 \mathrm{~B}$ in losses from these computer attacks between 1997 and 2003. ${ }^{17}$ Yet, these loss approximations and the methods of determination are often questionable. For example, other estimates have placed the losses Melissa and Love Bug virus at $\$ 80 \mathrm{~B}$ and $\$ 10 \mathrm{~B}$, respectively. ${ }^{18,19}$ The losses from these two viruses alone add up to more than the estimated \$65B in losses between 1997 and 2003. Estimates of damages from the Code Red virus are placed between $\$ 1.2 \mathrm{~B}$ and $\$ 8.7 \mathrm{~B}$ - a wide range. ${ }^{20,21}$ These loss estimates are usually made by multiplying the number of computers thought to be infected times the estimated cost to repair each PC.

Federal and state laws, with their statutory descriptions, provide additional insight into the nature of losses from cybercrimes. The following list of costs and damages are used to estimate a victim's statutory losses under state computer crime statutes. ${ }^{22}$

- Verification costs to check systems (diagnosisremediation)

- Restoration costs to put systems back online (testing)
- Market value or replacement value of the property or services

- destroyed

- Lost profits

- Reasonable value of loss caused by "unavailability"

- Investigation costs

- Past or future losses

- Injury suffered

- Loss of computer time (loss productivity)

- Cost of replacing lost data

The list includes a combination of tangible and intangible losses. For example, the damages from injuries suffered, lost profits, past or future losses, and system unavailability losses are intangible losses. Tangible losses are associated with restoration and verification, investigative actions, lost productivity, and the replacement of lost data.

In Section 18 U.S.C. 1029 and in Section 814 of the Patriot Act, the federal government identifies the following items as losses from cyber attacks.

- Responding to an attack

- Making a damage assessment

- Restoring the system

- Loss of revenues from the interruption

- "Other damages" related to an interruption of service

Losses of revenues from the interruption and "other damages" incorporate intangible damage valuations.

Today's traditional business insurance contracts may provide some coverage against cyber attacks. However, traditional business insurance policies do not provide insurance coverage for intangible losses such as lost computer data. ${ }^{23,24}$ Lloyd's of London, Chubb, and AIG are among the insurers providing cyber attack insurance for companies. ${ }^{25,26}$

Insurance for cyber attack coverage, when available, provides for first- and third-party liability coverage. ${ }^{27}$ First-party liability coverage is for direct damage to the insured from a cyber attack. Third-party liability provides for coverage from the negligent acts of the insured, as when the insured's computers are unknowingly used to launch an attack against a primary target. 
First-party cyber insurance can provide loss coverage for:

- Malicious destruction or alternation of information

- Theft of data such as credit card numbers

- Lost business income up to 12 months after the attack

- Extortion from threats such as introducing viruses into a network

- Introducing fraudulent information into a network

- Defamation

- Cost to repair and replace data

- Unintentional virus transmission

- Denial of service attacks

- IP infringement from web site squatters

- Illegitimate use of networks

- Defacement of a web site and related losses

- Coverage of extra expense incurred during a disruption

- External consultant fees

- Intellectual property infringement from the disclosure of trade secrets

- Rehabilitation expenses to re-establish the insured's reputation and market share

- Crisis communication expenses with clients to provide assurances the system is reliable and safe

Coverage for data theft, defamation, website defacement, and intellectual property infringement, if not contractually limited to specific dollar recoveries, can invite estimations of damages related to intangible factors.

\section{TRADITIONAL TANGIBLE LOSS ANALYSIS}

Credit card numbers at a bank website, program codes, lists of tax clients' probability scores for possible IRS tax challenges on a CPA's computer, copyrighted music and films, or a bid strategy document to be used on a government contract are examples of valuable data that can be stolen or damaged when a hacker gains unauthorized access to a network. Tangible losses from such a cyber attack are calculated based on the costs of system restoration. The total cost of system restoration is based on labor rates, materials, and overhead. If program code is destroyed or stolen in the attack, the direct costs of the work hours used to originally create the code may become part of the loss estimate. When the destroyed asset is not reconstructed, all developmental costs are considered tangible losses. All workers' restoration time used in diagnosing, restoring, checking and testing the network as well as replacing lost data are part of the tangible loss from a cyber attack when the damaged or destroyed asset is reconstructed.

Traditional loss analysis using tangible costs is illustrated in the following example with Memo Tech, a hypothetical software development company, with a new software product called F-Detect that was damaged in a cyber attack. In this illustration, it is assumed that Memo will reconstruct its F-Detect software. Memo Tech policies state that if market projections show that a software product under development does not have a $25 \%$ chance of gaining a $10 \%$ market share, the product is dropped. ${ }^{28}$ During the beta phase of new product testing and development market projections are tested each quarter, and the product has continued to meet its market share objectives. Experience has taught Memo Tech that it is better to drop a product if market projections are negative and incur losses equal to the product's development costs rather than continuing to develop a product with little likelihood of market success.

\section{Tangible loss valuation}

MemoTech, a manufacturer of IDS software, developed a new monitoring system called F-Detect. F-Detect, with many unique features, is projected to capture $10 \%$ of the IDS market. Memo spent one year and 12,000 work hours (developmental time $70 \%$; testing time $30 \%$ ) to create the system. Memo was ready to beta release F-Detect. Normally, the beta testing would last another year.

F-Detect was stolen two weeks before its beta release, and its related files and coding were destroyed. The attacker entered Memo's system through their web server. Memo's chief financial officer is developing an estimate of the loss from the attack. The original cost of developing the program included salaries and benefits of $\$ 50$ and $\$ 70$ per hour for development and testing, respectively. Overhead is charged to the development at \$10 per direct labor hour for all jobs at Memo. It is also estimated that managerial personnel were directly involved in developing the program for 100 days over each of the last 2 years. Total managerial salaries at the Memo are $\$ 300,000$. Memo estimates the original developmental costs of the software as $\$ 958,667$. 
Developmental cost (12,000 hours)

Dollar cost lost

\begin{tabular}{ll}
\hline $\begin{array}{l}\text { Technicians wages }(\$ 50 \\
(12,000 \times 0.70))\end{array}$ & $\$ 420,000$ \\
$\begin{array}{l}\text { Support services } \\
(\$ 10 \times 12,000)\end{array}$ & $\$ 120,000$ \\
$\begin{array}{l}\text { Managerial support to } \\
\text { F-Detect }\end{array}$ & $\$ 166,667$ \\
$\begin{array}{l}\text { Testing }(\$ 70 \\
(12,000 \times .30))\end{array}$ & $\$ 252,000$ \\
$\begin{array}{l}\text { Total developmental } \\
\text { cost of F-detect }\end{array}$ & $\$ 958,667$ \\
\hline
\end{tabular}

*Total annual salaries devoted to F-Detect: $(\$ 300,000 \times 100 / 360) \times 2$ years $=\$ 166,667$

The attacker was methodical in destroying coding, and over the next year, Memo's managers will devote 150 days and assign 10,000 work hours to restoring the F-Detect system prior to its commercial release. Memo estimates its direct costs of restoring F-Detect as $\$ 785,000$.

Reconstruction cost Dollar cost lost
$(10,000 \mathrm{~h})$

\begin{tabular}{ll}
$\begin{array}{l}\text { Technician wages }(\$ 50 \\
(10,000 \times 0.70))\end{array}$ & $\$ 350,000$ \\
$\begin{array}{l}\text { Support services } \\
(\$ 10 \times 10,000)\end{array}$ & $\$ 100,000$ \\
$\begin{array}{l}\text { Managerial support to } \\
\text { F-Detect* }\end{array}$ & $\$ 125,000$ \\
$\begin{array}{l}\text { Testing }[\$ 70 \\
(10,000 \times 0.30)]\end{array}$ & $\$ 210,000$ \\
Total Reconstruction & $\$ 785,000$ \\
Cost of F-Detect & \\
\hline
\end{tabular}

*\$300,000 $\times 150 / 360 \times 1$ year $=\$ 125,000$

If F-Detect is not reconstructed, the loss would be equal to the original developmental costs of $\$ 958,667$. Under this analysis, Memo goes ahead with the reconstruction, and the tangible loss from the cyber attack is the reconstruction costs of $\$ 785,000$. Once the reconstruction costs are incurred, Memo is back to the product developmental point existing before the attack.

In the example, all traditional costs related to labor, materials and overhead are aggregated in estimating the loss. Yet, there are other significant costs that are not included in such traditional loss estimates. For example, if a company has to assign its resources to reconstruct software damaged or destroyed in a cyber attack, and its resources are limited, it will have to forego new opportunities that it could otherwise have pursued. There is an opportunity cost for the company in giving up these additional business opportunities.
In addition, the company's current partnering relationships or business opportunities may suffer as a result of the attack. These financial effects may include canceled contracts, delayed implementation of a new product, the execution of penalty clauses in contracts, and reduced market share. If these effects extend beyond a one-year period, the loss analysis includes time value of money considerations.

If these factors were considered, how would it change the loss valuation in the Memo Tech example? The original developmental costs do not change, but the reconstruction cost and consequential loss must be increased by any lost business opportunities and potential losses in market share arising from the cyber attack. The following loss analysis takes these intangible factors into account.

\section{Present value loss valuation}

Managers at Memo believe the loss from the cyber attack is larger than calculated when only considering labor, material, and overhead costs. If MemoTech had released its commercial software on schedule in one year, Memo's management estimates they could have captured $10 \%$ of the IDS market and earned an extra $\$ 2 \mathrm{M}$ in profits per year for five years. Before the attack, Memo estimates it had a $60 \%$ chance of gaining a $10 \%$ market share, that is, a $40 \%$ probability of less than a $10 \%$ market share.

After the attack, the probability of a $10 \%$ market share has been reduced to $40 \%$, that is, a $60 \%$ chance of having less than a $10 \%$ market share. If market projections were to change to signal that Memo had a $<25 \%$ chance of obtaining its $10 \%$ market share, Memo would abandon F-Detect.

Memo believes that a better way to value its losses is to calculate the expected present value of the profits lost due to the delay in entering the market caused by the attack. Memo believes that this is a more accurate estimate of the loss than merely the reconstruction costs.

Before the attack, Memo estimated a $60 \%$ chance of earning $\$ 2 \mathrm{M}$ in profits annually over the next 5 years with its $10 \%$ market share. With Memo's cost of capital of $15 \%$, the present value of this revenue stream is $\$ 6,704,320$. ${ }^{*}$ The total loss due to the cyber attack is estimated as follows:

Expected value of future lost earnings

$((\$ 6,704,310 \times 0.60)+(\$ 0 * * 0.40)) \quad \$ 4,022,586$ 
Now, Memo needs a year to reconstruct F-Detect. $*{ }^{* *}$ Consequently, its ability to achieve a $10 \%$ market share is reduced to $40 \%$, and its expectation of future profit in such a market is estimated to decrease to $\$ 1.75 \mathrm{M}$ per year over the next four years from the product release date (reduced product life) resulting in a present value of $\$ 4,996,215 .{ }^{* * *}$ Memo also estimates an opportunity cost of $\$ 125,000$ associated with using its resources to reconstruct F-Detect. The loss incurred if Memo reconstructs F-Detect is estimated as follows:

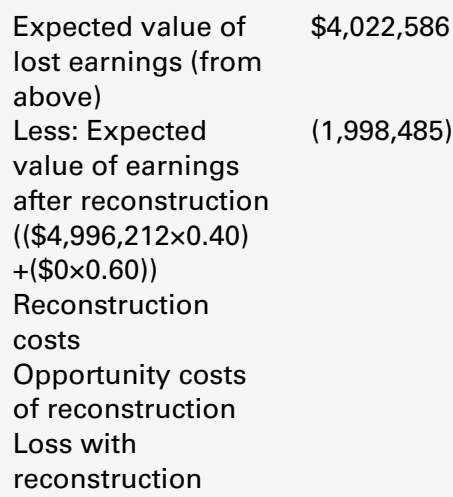

From this perspective, Memo does not view its loss as $\$ 785,000$ (the reconstruction costs). Instead, if Memo goes ahead with the reconstruction, Memo views its loss as the difference between the expected value of its profits before and after the attack, combined with the reconstruction and opportunity costs, or $\$ 2,934,101$ (lost profits of $\$ 2,024,101$ plus reconstruction costs of $\$ 785,000$ and opportunity costs of $\$ 125,000)$.

${ }^{*}$ An annuity of $\$ 2 M$ for 5 years discounted at $15 \%$.

**Memo will not market products with a projected market share below $10 \%$.

***For illustrative purposes, the different release dates are not included in the present value analysis.

***An annuity of $\$ 1.75 \mathrm{M}$ for 4 years discounted at $15 \%$.

In this estimate, Memo's managers are moving beyond traditional loss valuation based solely on labor, materials, and overhead, as they try to place a value on a negative change in a future business opportunity. Although they are attempting to place a valuation on their future loss arising from the attack, they have not fully succeeded. The analysis does not consider the new strategic environment under which Memo's managers will be making decisions about continuing the development of F-Detect. Standard present value analysis does not fully account for these strategic factors, but real options analysis can provide a means for valuing the intangible losses associated with future business opportunities.

\section{REAL OPTIONS ANALYSIS - AN INTRODUCTION}

Real options analysis requires the existence of several underlying criteria. First, there must be managerial flexibility, and secondly there must be uncertainty about a future event. Managerial flexibility is related to decisions about abandoning a project, going forward, shrinking the size (and cost) of the project, temporarily shutting it down, expanding the scope of the project, deferring or advancing the start date, or totally abandoning the investment. Managerial flexibility allows for a decision made at one point in time to be revised, reversed, or modified as conditions change. If these choices are available to managers, the option has measurable value to the company.

For example, early developmental expenditures on a new product may only be made to allow a high-tech company to fully expand into a new software market in the future if conditions are favorable to the expansion. Such outlays enable the company to be positioned to enter the market without fully committing the company to the project until market conditions stabilize. Consequently, a software development company creates a beta version of its software, but full funding for a commercial version is held back until the sales picture becomes more certain. Yet, if the company had not made the initial expenditures to develop the beta software, it would not be in a position to expand into a new market. The initial investment has created a strategic option for product expansion, and that option has a measurable value.

If an intruder destroys program code in the beta version of a new software product, the intruder also damages the company's strategic position to enter a new market. Thus, two losses have occurred. One loss is the reconstruction costs of the re-developed software, but another loss is the company's impaired strategic option 
to expand into a new profitable market. In such a case, the total loss is equal to the reconstruction costs, and the diminished value of the option. ${ }^{29}$

A second criterion for real options valuation is related to the uncertainty of the occurrence of a future event. Real options have a value if uncertainty about a business decision can be resolved during a future time period. Risk is defined as a random variable with a known probability. On the other hand, uncertainty is considered to be a random variable with an unknown probability distribution. In order to convert uncertainty into risk, subjective probabilities, as defined by management, need to be estimated for an event. As will be seen later, this is the procedure that is followed with the binominal distribution tree. If there is no uncertainty about a future action, the option has no value. Therefore, both uncertainty and managerial flexibility underlie real options analysis.

Real options valuation requires that: (1) there is uncertainty about the outcome of a project; (2) the project can be delayed, up to a point, without risking it; (3) managers are willing to undertake a project with a negative net present value (NPV); (4) managers are willing to lose the funds they have initially invested in a pilot project; and (5) managers are not contractually obligated to pursue the project or make additional investments.

Traditional NPV analysis does not work well as a valuation technique where there is significant uncertainty about future events. The ability to delay a project arising from managerial flexibility is also not recognized in traditional NPV analysis. To overcome this problem, NPV calculations may need to be highly positive for managers to financially commit themselves to making an investment. Essentially, a highly positive NPV assigns a value to intangible factors that cannot be properly analyzed using traditional present value analysis. For these reasons, real option analysis has advantages in evaluating projects where uncertainty and managerial flexibility exist.

\section{REAL OPTIONS CALCULATIONS FOR CAPITAL INVESTMENTS}

Real options valuation uses decision tree analysis (DTA) with discrete time segments to develop an option-pricing and valuation model. ${ }^{30,31}$
DTA involves structuring a capital investment project within a timed decision tree using single discrete option choices. Each branch of the decision tree represents the payoff associated with a particular managerial decision (eg, good news vs bad news). Subjective probabilities, as set by management, are assigned to each potential upward or downward outcome at each decision node or branch in the tree.

The analysis begins by determining the present value of the investment, initially ignoring any real options, and using a risk-adjusted discount rate represented by the weightedaverage cost of capital $(k)$ to compute present values. Unlike traditional present value analysis, the initial present value of the investment is calculated by weighting each branch's payoff by its associated probability and calculating the combined present value, using $(k)$, of the branches. ${ }^{32}$ For a single-period model, the present value, $P V$, of a binomial decision tree is calculated as:

$$
P V=\frac{p C F_{u}+(1-p) C F_{d}}{(1+k)},
$$

where $p$ is the objective probability of up state, $(1-p)$ is the objective probability of down state, $C F_{u}$ is the cash flow in the up state, $C F_{d}$ is the cash flow in the down state, $k$ is the weighted average cost of capital.

As illustrated in Figure 1, the potential outcomes for Project $\mathrm{ABC}$ are revenues of either $\$ 50 \mathrm{M}$ or $\$ 15 \mathrm{M}$, with an upward probability of 50 per cent (and thus a downward probability of 50 per cent). Given a cost of capital of 10 per cent, the expected PV of the projected return is

\section{0\% Weighted Average Cost of Capital} \$30M Capital Investment

Project $A B C$ represents a project that cannot be delayed

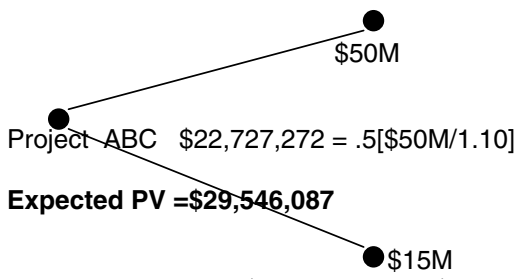

$\$ 6,818,815=.5[\$ 15 \mathrm{M} / 1.10]$

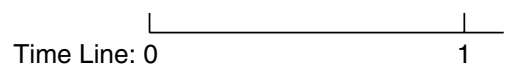

Figure 1: Project $A B C$ using PV analysis with a 1-year investment and a binominal tree results in a negative NPV of $\$ 453,913$ 
$\$ 29,546,087(\$ 22,727,272+\$ 6,818,815) .{ }^{33}$ With an initial capital investment of $\$ 30 \mathrm{M}$, the project has a negative NPV of $\$ 453,913 .{ }^{34}$

This analysis provides a baseline valuation of Project ABC without considering real options. Managerial flexibility in decision-making, that is, the ability to wait, reduces investment risk, as managers can change investment strategies as the future becomes more certain. Such flexibility affects the future cash flows from a project and changes the risk characteristics of the related capital investments. Therefore, the risk-adjusted discount rate $(k)$ previously used to determine the present value of the project without real options is inappropriate for calculations when managerial flexibility and uncertainty are considered.

To account for this reduction in risk, Copeland and Antikarov (2003) ${ }^{35}$ suggest calculating risk-neutral probabilities on the binominal tree using the risk-free interest rate associated with the project. These adjustments result in solving for the new upward and downward risk-neutral probabilities when a riskfree interest rate is used instead of $(k) .{ }^{36}$ Consequently, the risk-free rate adjustment inherently changes the upward and downward probabilities on the binominal tree. These riskneutral probabilities, $p_{u}$ and $p_{d}$, are then used to determine the present value of the project. The risk-neutral upward probability is calculated as:

$$
p_{u}=\frac{\left(1+r_{f}\right)-d}{u-d},
$$

where $r_{f}$ is the risk-free interest rate $(0.04), u$ is the up parameter $(\$ 50,000,000 / \$ 30,000,000)=$ $1.67, d$ is the down parameter $(\$ 15,000,000$ / $\$ 30,000,000)=0.50$.

The upward and downward parameters represent the two possible returns from the initial investment of $\$ 30 \mathrm{M}$. Using the data for Project $\mathrm{ABC}$ and assuming the risk-free rate of interest is 4.0 per cent, that is, the 90 -day Treasury bill rate, the risk-neutral probability for upward movement on the binominal tree is calculated as forty-six percent. This is the upward probability $\left(p_{u}\right)$ that would exist when investors are indifferent to risk. ${ }^{37}$

$$
\begin{gathered}
p_{u}=\frac{(1+.04)-0.50}{1.67-0.50} \\
p_{u}=0.46
\end{gathered}
$$

As the value of the upward probability $(p u)$ is 46 per cent, the downward probability $(p d)$ must be 54 per cent. ${ }^{38}$

$$
\begin{aligned}
& p_{d}=1-p_{u} \\
& p_{d}=(1-0.46)=0.54
\end{aligned}
$$

Weighting the values of the option in the up and down state by the risk-neutral probabilities and discounting at the risk-free rate of $4.0 \%, r f$, yields the present value of the project with real options. In Figure 2, there is a zero value placed on the downward state, that is, loss of $\$ 15.45 \mathrm{M}$, as the delay in implementing the ABC Project would allow managers to curtail the investment if it was only going to return $\$ 15 \mathrm{M}$ to the company and create a loss. The time delay reduces the uncertainty surrounding the project, and thus the lower risk-free rate becomes a better estimator of the project's internal risk.

Assuming the ABC Project can be delayed for 1 year while a determination is made whether to continue with the project, real options analysis shows the NPV of the project is now $\$ 8,315,385$ whereas before the project had a negative NPV of $\$ 453,913$. Of course, delaying the project causes its cost to increase by $\$ 1,200,000$. $^{39}$

As a result, the value of the option to wait 1 year is equal to $\$ 8,769,298 .^{40}$ For a capital investment, the value of a real option represents the difference between the NPV of the project including options using the risk-free rate of interest compared with the NPV of the project without options and applying an interest rate that includes a risk premium. ${ }^{41}$

4.0\% Discount Rate (Risk-free rate) \$31.2M Capital Investment

Project $\mathrm{ABC}$ represents a project that can be delayed

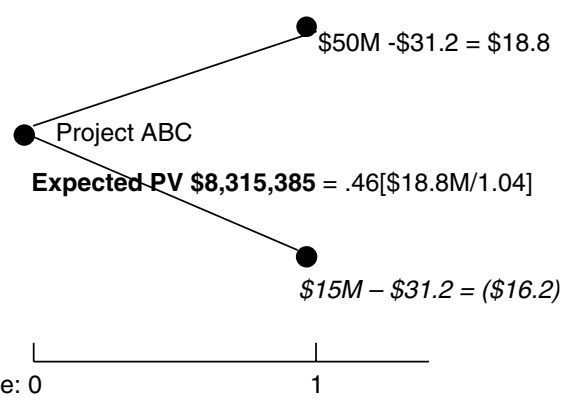

Time Line: 0
Figure 2: Project $A B C$ using $P V$ analysis with a 1-year investment delay and a binominal tree results in a positive NPV of $\$ 8,315,385$ 


\section{USING REAL OPTIONS TO VALUE LOSSES FROM CYBER ATTACKS}

Many business investment projects fit within the constraints of a real options capital investment model. Such projects have a projected time frame for implementation, and at a critical juncture, before implementation, managers may continue or abandon these projects. Such an analysis is particularly relevant to products with a life cycle that may be shortened by the introduction of competing products, fast technical obsolescence, or other disruptions of the market. ${ }^{42}$ Real options methodologies are particularly pertinent to software products as managerial flexibility and risk are important factors in marketing new software. If a flexible business plan is negatively affected by a cyber attack, real options need to be valued to learn the entire extent of damages from the attack. Loss calculations that only recognize the tangible costs, lost earnings, and opportunity costs from a cyber attack miscalculate the loss, as the effect on the value of the real options are not included in the estimate. (Figure 3).

\section{Real options loss valuation}

The managers at Memo are interested in using real options valuation to calculate the loss they experienced from the cyber attack on F-Detect. Before the attack, Memo had an opportunity to earn revenues with a present value of $\$ 6,704,320 .{ }^{43}$ After the attack, Memo projected the present value of the revenue stream would decrease to $\$ 4,996,215$, and their ability to capture a $10 \%$ market share was reduced from 60 to $40 \%$. In 3 , there is a $12 \%$ upward probability for F-Detect and quarterly option expenditures are shown as one payment of $\$ 766,934(\$ 958,667 \times 0.80) .44$ Using the $4 \%$ risk-free rate of interest, the value of the real options prior to the attack was $\$ 685,083$ as shown in 3. Memo would not continue developing F-Detect if the market was less than $10 \%$, that is, the situation on the downward branch on the binomial tree in 3 . The purpose of the analysis is not to compare NPV with real options methods, but to identify the value of the real option before and after the cyber attack. Both before and after the attack, Memo has the option to stop the development or reconstruction of F-Detect. The value of the option before the attack is determined as $\$ 685,083$ as shown in 3. The lost business opportunities are not $\$ 2,024,106$ $(4,022,592-\$ 1,998,486)$ as previously calculated.
Instead, the changed value of the lost option better represents the loss to Memo.

In making the loss determination, Memo recalculated the value of the real option based on its reduced value, and the present value of the revenue stream obtainable after reconstruction. In such a case, the loss from the cyber attack is the difference between the real option's value under the two alternatives, plus the costs of reconstructing F-Detect and any opportunity costs. The expenditures for reconstruction are assumed to follow the same quarterly expenditure pattern exhibited with the development costs. Therefore, only $80 \%$ of these costs or $\$ 628,000$ is used in computing the value of the real option $(\$ 785,000 \times 0.80)$. 4 illustrates how the value of the option $(\$ 63,003)$ is calculated after the attack and reconstruction. ${ }^{45}$

$\begin{array}{ll}\begin{array}{l}\text { Decrease in real } \\ \text { option Value }\end{array} & =\$ 622,080 \\ \begin{array}{l}\text { (\$685,083- } \$ 63,003) \\ \text { Add: opportunity cost }\end{array} & =125,000 \\ \begin{array}{l}\text { Add: costs of } \\ \text { reconstruction }\end{array} & =785,000 \\ \text { Loss from cyber attack } & \$ 1,532,080\end{array}$

It is assumed that after the reconstruction is begun, Memo's managers still have the flexibility to curtail F-Detect's development should it become clear the product could not achieve a $10 \%$ market penetration.

Table 1 summarizes the results of valuing Memo's loss under the three alternative approaches and assuming F-Detect is reconstructed. In Table 1, it can be seen that tangible loss analysis undervalues the loss, as it does not account for the business opportunities that have been lost. Present value analysis, which recognizes the value of lost profits overvalues

4\% Discount Rate (Risk-free rate)

Pt. 1 represents the initiation of the project

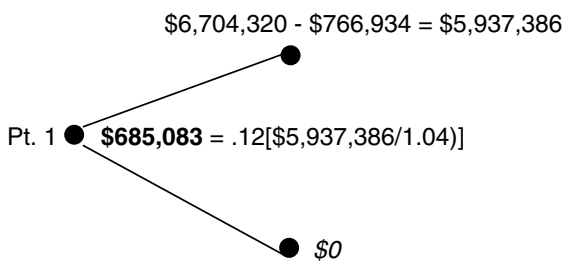

Time Line: $\quad$\begin{tabular}{ll}
$L$ & 1 \\
\hline & 0
\end{tabular}

Figure 3: Real option value for F-Detect before attack 
Table 1: Loss Valuations

\begin{tabular}{ll}
\hline Valuation method & Decision: reconstruct \\
\hline $\begin{array}{l}\text { Tangible loss analysis } \\
\text { Present value loss }\end{array}$ & $\$ \mathbf{7 8 5 , 0 0 0}$ \\
$\begin{array}{l}\text { analysis } \\
\text { Real options loss } \\
\text { analysis }\end{array}$ & $\$ 1,532,080$ \\
\hline
\end{tabular}

the loss because it does not recognize the value associated with flexibility and manager's ability to delay a decision. Real options analysis provides the most accurate measure of the loss incurred by recognizing the intangible factors related to decision making and business continuity by using a discount rate that reflects these factors. In developing these estimates, it was assumed that the delay in F-Detect's release date caused a reduction in the future revenue stream available to Memo. This assumption would need to be analyzed as it may not be true in every case.

In essence, the cyber attack provided for a delay that allowed managers more time to evaluate a market with lowered returns as competition in the market became more intense. The purpose of the analysis is not to determine whether or not F-Detect is to be reconstructed or not, but rather to more accurately identify the total loss incurred by Memo. ${ }^{46}$

\section{REAL OPTIONS AND BUSINESS APPLICATIONS}

With this loss estimate, the managers at Memo can make informed business decisions. With a better understanding of how to evaluate potential losses, Memo can approach their insurance carriers, ahead of time, with the proper level of requests for loss coverage. Correctly qualifying a potential loss allows Memo's managers to carry the proper loss coverage. Memo's insurance cost may even be reduced. Or, the more specific identification of intangible losses may require managers to select new insurance providers who understand Memo's business needs and who can provide insurance for such events. Further, real options analysis allows Memo to make a better estimate of the actual loss incurred after an attack. Using this loss analysis, managers can
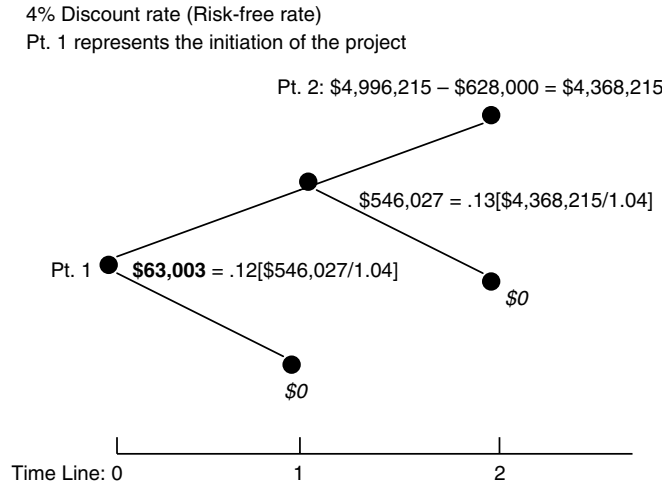

Figure 4: Real option value for F-Detect with reconstruction delay

effectively develop better financial arguments for law enforcement actions, and in civil or criminal proceedings, they can demonstrate the extent of damages suffered by the company.

Although the analysis on one hand reflects the amount of loss that can be incurred if digital assets are lost or damaged, on the other hand, the loss also identifies the underlying value of the assets to the company. To make informed management decisions, such as the return on capital invested or to make new resource allocations, managers need to know the total worth of the asset under consideration. For many of today's digital assets, net worth is tied to intangible values that extend beyond the accounting values recognized in a traditional balance sheet. The methods outlined here assist managers in valuing losses, but they also provide guidance for recognizing the underlying asset values upon which effective business decisions need to be based.

Beyond these immediate valuation considerations, an analysis based on forecasted market changes allows managers to consider long-term product strategies in the face of changing conditions. Such strategies allow for evaluating future trade-offs synergies and result in more informed business decisions. These intricate time-series market synergies often do not get measured with standard present value techniques using an up-front "go or no go" decision focus on projects.

\section{CONCLUSION}

The intangible value of an asset can be shaped by the events that occur around it. Here, one 
such event, a cyber attack, has been analyzed. The attack caused changes to occur in the continuity of business operations, and those changes have to be valued using a model that will more fully consider all the factors that have changed. Standard present value analysis evaluates business decisions with an underlying assumption that future changes are static. Consequently, present value analysis may result in estimations that overvalue asset losses.

To make informed business judgments regarding corporate strategies, managers need to know the underlying value of their assets. These measures must include more than the summation of labor, materials and overhead expenditures when intangible values are present and significant. Such an approach is especially important for digital assets whose net worth is strongly based on intangible values. The valuation of these assets, particularly, goes beyond the traditional accounting charges associated with them. It is argued here that real options analysis provides a means to more accurately quantify the value and potential loss inherent in digital assets.

\section{References}

1 Cyber attacks are considered to be any digital attack against a company's assets using a computer as the weapon of attack.

2 In some cases, these assets maintain their value only if they continue to remain in an electronic format, and they exist within a computer or any internal or external company device connected to a computer.

3 For a federal crime, the damages must exceed $\$ 5,000$. For state computer crimes, the dollar damages vary.

4 The losses recognized under an insurance claim usually differ from the loss recognition developed for courtroom proceedings.

5 Berkowitz, G (1999) 'Incident Cost Analysis and Modeling Project II (I-CAMPII)', USENIX News, available at:. http://www.usenix.org/publications/ login1999-6/icamp.html.

6 Madigan, E., Petrulich, C. and Motuk, K. (2004) The Cost of Non-compliance: When Policies Fail. Proceedings of the 32nd Annual ACM SIGUCCS Conference, Baltimore.

7 Mercuri, R. (2003) 'Analyzing security costs', Communications of the ACM, Vol. 46, No. 6, pp. 15-18.
8 Tan, D. (2003) Quantitative Risk Analysis Step-byStep. Sans Institute, Bethesda, MD.

9 The Incident Cost Analysis and Modeling Projects (I-CAMP I and II) were research studies conducted in the Office of Policy Development at the University of Michigan in 1999 and 2000. The study used survey results to estimate the cost of rectifying cyber attacks at universities. Beyond the traditional accounting costs of labor and overhead, the study considered but only incidentally addressed unquantifiable costs such as legal liability, diminished reputation, and psychological costs.

10 Suh, B. and Han, I. (2002) 'The IS risk analysis based on a business model', Information and Management, Vol. 41, No. 2, pp. 149-158.

11 Traditional loss valuation methods tend to use: (1) an income approach based on present value analysis of the income streams assigned to an asset; (2) a market approach where the fair market value or the current replacement cost of the asset is estimated; or (3) the cost approach where values are based on historical purchase costs.

12 Although the techniques used to launch a cyber attack and carry out cyber terrorism are similar, there is an underlying difference between these two crimes. Cyber terror is politically driven, and focused on causing large-scale damage to critical national infrastructure. Such extensive politically driven attacks are not considered here.

13 Sandoval, G. (2002) 'Why Hackers escape', CET News.com, May 14, 2002. http://news.com. com/2009-1017_3-912708.html.

14 Hesseldahl, A. (2001) 'Hackers Hammer Microsoft', Forbes.com, January 26, 2001. http:// www.forbes.com/2001/01/26/0126msft.html.

15Loeb, M.P. (2004) 'Cybercrimes' true price: crime may not pay, but someone has to pick up the cost', InformationWeek, March 30, 2004.. http:// www.informationweek.com/showArticle.jhtml?arti cleID $=18402607$.

16 The author found that companies lost an average of slightly more than 5 per cent of their market valuation from cybercrimes related to confidentiality breaches.

17 Ramirez, C.E. (2003) 'Why viruses make business sick', Detroit News, Technology. September 7, 2003. http://www.detnews.com/2003/technology/ 0309/08/a01-264241.htm.

18 Poulsen, K. (2001) 'Justice delayed for Melissa author', Security Focus. July 30, 2001. http://www. securityfocus.com/news/230.

19 Svensson, P. (2000) 'A 'love bug' costs billions in time and data losses', The Cincinnati Enquirer, May 6, 2000. http://enquirer.com/ editions/2000/05/06/fin_love_bug_costs.html. 
20 Godoy, M. (2001) Code Red II Nastier Bug. TechTV, August 6, 2001. http://www.techtv.com/news/ print/0,23102,3340770,00.html.

21 Greene, T.C. (2001) 'Code red hysteria - \$8.7B in damage estimated', The Register, August 2, 2001. http://www.theregister.co.uk/content/56/20779. html.

22 CAL. PENAL CODE Section 502; DEL. CODE ANN. Title II, Part 1, Chapter 5, Sub. Chapter III 931-939; GA. CODE ANN. Section 16-9-91 and 16-9-9-16-9-94; HAW. REV. STAT. ANN. Section 708-890 and 709-895.7; IOWA CODE ANN. Title XVI, subtitle 1, Section 622.51A, 702.1A, 702.14, 714.1, 716.6B; MASS. GEN. LAWS, Chapter 266, 120F; MINN. STAT. Section 609.89-609.891; NEV. REV. STAT. ANN. Section 205.4765-205-513; N.H. REV. STAT. ANN. Section 638:1-638:19; N.J. STAT. ANN. Section 2A:38A-1-2A:38A-6 and 2C:20-23-2C:20-32; OKLA. STAT. ANN. Title 21, 1951-1958; PA. CONS. STAT. ANN. Chapter 18, 18-3993; W.VA. CODE ANN. Section 61-3C-4-61-3C-21.

23 Rivard, C.L. and Rossi, M.A. (2001a) 'Is computer data 'tangible property' or subject to 'physical loss or damage?' Part 1', International Risk Management Institute, Expert Commentary. August 2001,. http:// www.irmi.com/expert/articles/rossi008.asp.

24 Rivard, C.L. and Rossi, M.A. (2001b) 'Is computer data 'tangible property' or subject to 'physical loss or damage?' Part 2', International Risk Management Institute, Expert Commentary, November 2001. http://www.irmi.com/expert/ articles/rossi009.asp.

25 Enos, L. (2000) 'Lloyd's of London to offer Hacker insurance. July 10, 2000 E-Commerce Times, http://www.ecommercetimes.com/story/3730. html.

26 Gordon, L., Loeb, M. and Sohail, T. (2003) 'A framework for using insurance for cyber-risk management', Communications of the ACM, Vol. 46, No. 3, pp. 81-85.

27 Before providing cyber attack coverage to a client, an insurance company is likely to require an evaluation of the client's site to assess the nature of the insurance risks. An experienced security assessment firm will provide a thorough due diligent security audit of the network before any policy is issued. Factors such as the following are evaluated to determine risk exposures: (1) number of business partners with access to the network; (2) level of hosting services provided; (3) type of e-commerce conducted; (4) number of external network connections; (5) implementation of a written security policy; (6) use of encryption; (7) operating system used on the network; (8) use of backup copies and logging procedures; and (9) use of security audits.
28 Many products have specific market criteria that they must meet in order to be considered for further development. Therefore, a $10 \%$ penetration policy for F-Detect is not usual.

29 Such options can be quantified using BlackScholes model methodologies. See (1) Fischer Black and Myron S. Scholes. 1973. The Pricing of options and corporate liabilities. Journal of Political Economy 81 (May-June): 637-659. (2) Martha Amram and Nalin Kulatilaka, Real Options: Managing Strategic Investment in an Uncertain World. (Boston, MA: Harvard Business School Press, 1999). Amram M., Kulatilaka N. (1999) Real Options: Managing Strategic Investment in an Uncertain World. Harvard Business School Press, Boston, MA (3) Lenos Trigeorgis, Real Options in Capital Investment: Models, Strategies and Applications (Westport, CT: Praeger: 1995). Trigeorgis L. (1995) Real Options in Capital Investment: Models, Strategies and Applications. Praeger, Westport, CT.

(4) Lenos Trigeorgis, Real Options: Managerial Flexibility and Strategy in Resource Allocation (Cambridge, MA: The MIT Press, 1999). Trigeorgis L. (1999) Real Options: Managerial Flexibility and Strategy in Resource Allocation. The MIT Press, Cambridge, MA. Although real options share similar characteristics with financial options, there are distinct differences that make financial option pricing models, such as Black and Scholes (1973). Black F., Scholes M. S. (1973) The Pricing of Options and Corporate Liabilities. Journal of Political Economy 81 (May-June): 637659. inappropriate for valuing real option investments. For example, Black-Scholes assumes a liquid market for the underlying asset and observable market prices. Real options, however, are typically not traded and their valuation requires the use of judgmental probabilities.

30 Cox, J.C., Ross, S.A. and Rubinstein, M. (1979) 'Option pricing: a simplified approach', Journal of Financial Economics, Vol. 7, No. (3), pp. 229-264.

31 Cox, J.C. and Rubinstein, M. (1985) Options Markets. Prentice-Hall Inc., Englewood Cliffs, NJ.

32 For illustrative purposes, it will be assumed that there is only one best upward and one worst downward choice for the investment, but a middle alternative could be assumed. Here, the purpose is to explain real option analysis, not all its ramifications.

33 In traditional present value analysis, the weighted average cost of capital is the rate typically used to discount any future cash inflows from a capital investment project.

34 The net present value of the project is a negative $\$ 453,913(\$ 29,546,087-\$ 30,000,000)$. The present value of the two possible outcomes discounted at 
$10 \%$ and multiplied by the probability of their occurrence equals $\$ 29,546,087$ as shown in Figure 1.

35 Copeland, T.E. and Antikarov, V. (2003) Real Options: A Practitioners Guide. Thomson, Texere, NY.

36 The risk-free rate of interest is a theoretical rate that is assumed to be completely free of any investment risk. The 90-day Treasury bill rate is usually used as the risk-free rate of interest. Riskneutral probabilities are the subjective probabilities for a risk-neutral individual who is unconcerned about risk and all returns receive the risk-free rate. Risk-neutral probabilities must be positive and sum to one. Essentially risk-neutral probabilities view the choices based on the characteristics of the option without incorporating additional cost for outside risk related payments (Copeland and Antikrov 2003).

37 The upward probability, taking into account the risk-free rate of interest can also be calculated as follows:

$$
\begin{aligned}
& p_{n}=\frac{(1.04 \times 30)-15}{50-15} \\
& p_{n}=0.46
\end{aligned}
$$

38 The two probabilities must sum to one.

39 It is assumed that the delay will cause the cost of the project $(\$ 30 \mathrm{M})$ to increase by 4.0 per cent (risk-free rate) or $\$ 1,200,000$. The total cost of the project, $\$ 31,200,000$, will become a cash outflow after the 1-year delay, not at the beginning of the project as in the previous example (the option allows for this delay). The option's NPV is a positive $\$ 8,315,385$. This indicates that the option added value of $\$ 8,769,298(\$ 8,315,385+\$ 453,913)$.

40 The value of the real option is $\$ 8,769,298$. This represents the difference between the net present value without considering the option, a negative $\$ 453,913$, and the net present value of the cash flows after the option is taken into account or $\$ 8,315,385$.
41 Using this approach, the value of a real option can be calculated in four steps: (1) value the project without real options using discounted cash flows and the risk-adjusted discount factor; (2) calculate the risk-neutral probabilities (3) determine the value of the project with the option using risk-neutral probabilities and the risk-free rate; (4) compute the value of the option as the difference between the value of the project calculated with and without real options.

42 Life cycle refers to the period from the creation to the withdrawal or retirement of a product. Generally the product life of software is short. An indication of software life is the usual depreciation schedule of 3-5 years used to depreciate 'off-theshelf' software.

43 See previous section on present value valuations.

44 Managers at F-Detect are assumed to be indifferent to risk because of their ability to delay the release of the product as the beta version of the product was in limited release. Additionally, they can abandon the product if it does not meet market expectations. The risk-neutral probability is calculated as: $p_{u}=\left(\left(1+r_{f}\right)-d\right) /(u-d)$ where: $r f=$ the risk-free interest rate (0.04), $u=$ up parameter $\$ 6,70$ $4,320 / \$ 766,934=8.74, d=$ down parameter $=0$ and, $p_{u}=((1+.04)-0) /(8.74-0) ; p_{u}=0.12$.

45 The original development costs of $\$ 958,667$ are reduced by $80 \%$ and used in the analysis. The analysis is based on the value of the real option after an additional year is needed to reconstruct F-Detect. Thirteen per cent represents the upward probability calculated as follows: The risk-neutral probability is calculated as: $p_{u}=\left(\left(1+r_{f}\right)-d\right) /(u-d)$ where: $r f=$ the risk-free interest rate (.04), $u=$ up parameter $\$ 4,996,215 / \$ 628,000=7.9, d=$ down parameter $=0$ and, $p_{u}=((1+0.04)-0) /(7.96-0) ; p_{u}=0.13$.

46 A continuing underlying assumption in the Memo example is that the company wants to maintain its competitive position in the IDS market, and therefore it must reconstruct F-Detect. 